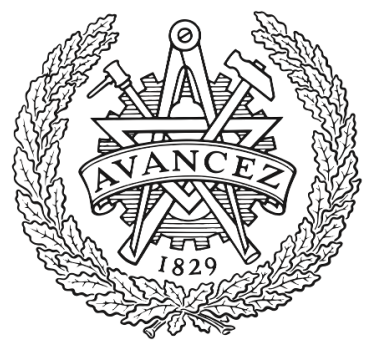

CHALMERS

UNIVERSITY OF TECHNOLOGY

\title{
Photoluminescence Properties and Fabrication of Red-Emitting LEDs based on Ca9Eu(VO4)(7) Phosphor
}

Downloaded from: https://research.chalmers.se, 2023-04-26 01:17 UTC

Citation for the original published paper (version of record):

Sharma, S., Tingberg, T., Carrasco, I. et al (2020). Photoluminescence Properties and Fabrication of Red-Emitting LEDs based on Ca9Eu(VO4)(7)

Phosphor. ECS Journal of Solid State Science and Technology, 9(1).

http://dx.doi.org/10.1149/2.0052001JSS

N.B. When citing this work, cite the original published paper. 
OPEN ACCESS

\section{Photoluminescence Properties and Fabrication of Red-Emitting LEDs based on $\mathrm{Ca}_{9} \mathrm{Eu}\left(\mathrm{VO}_{4}\right)_{7}$ Phosphor}

To cite this article: Suchinder K. Sharma et al 2020 ECS J. Solid State Sci. Technol. 9016004

View the article online for updates and enhancements. 


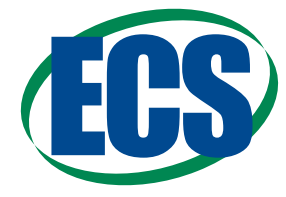

\title{
Photoluminescence Properties and Fabrication of Red-Emitting LEDs based on $\mathrm{Ca}_{9} \mathrm{Eu}\left(\mathrm{VO}_{4}\right)_{7}$ Phosphor
}

\author{
Suchinder K. Sharma, ${ }^{1, a, b}$ Tobias Tingberg, ${ }^{2}$ Irene Carrasco, ${ }^{3, c}$ Marco Bettinelli, ${ }^{3}$ \\ Dan Kuylenstierna, ${ }^{2}$ and Maths Karlsson $\oplus^{1, z}$ \\ ${ }^{1}$ Department of Chemistry and Chemical Engineering, Chalmers University of Technology, SE-412 96 Göteborg, \\ Sweden \\ ${ }^{2}$ Microwave Electronics Laboratory, Department of Microtechnology and Nanoscience, Chalmers University of \\ Technology, SE-412 96 Göteborg, Sweden \\ ${ }^{3}$ Luminescent Materials Laboratory, Department of Biotechnology, University of Verona, and INSTM, UdR Verona, \\ 37134 Verona, Italy
}

\begin{abstract}
We study the photoluminescence properties of the red-emitting phosphor $\mathrm{Ca}_{9} \mathrm{Eu}\left(\mathrm{VO}_{4}\right)_{7}$ and establish a strong red emission centered at $613 \mathrm{~nm}$ under excitation at $395 \mathrm{~nm}$ (near ultra violet light, near-UV light) due to the intra-configurational ${ }^{5} \mathrm{D}_{0} \rightarrow{ }^{7} \mathrm{~F}_{2}$ transition within the $4 \mathrm{f}^{6}$ configuration of the $\mathrm{Eu}^{3+}$ ions. The intensity of the emitted light decreases with increasing temperature and at $\mathrm{T}=$ $470 \mathrm{~K}$ about $50 \%$ of the intensity of the emitted light at room temperature is lost. Five different red-LED prototypes were constructed by applying a mixture of $\mathrm{Ca}_{9} \mathrm{Eu}\left(\mathrm{VO}_{4}\right)_{7}$ phosphor and silicone gel on the headers of near-UV LED chips. The prototypes showed a color output from violet for the lowest phosphor concentration (133 g phosphor /l silicone gel), reaching an almost pure red-light output for the highest phosphor concentration ( $670 \mathrm{~g}$ phosphor $/ 1$ silicone gel). The luminous efficiency of optical radiation (LER) was found to decrease slightly with increasing applied current. For the highest phosphor concentration, the LER decreases from $238 \mathrm{lmW}^{-1}$ for $1 \mathrm{~mA}$ current supply to $235 \mathrm{lmW}^{-1}$ for $18 \mathrm{~mA}$ current supply. The external quantum efficiency decreased from $7.33 \%$ for the lowest phosphor containing LED prototype to $4.13 \%$ for the highest one.

(C) The Author(s) 2019. Published by ECS. This is an open access article distributed under the terms of the Creative Commons Attribution 4.0 License (CC BY, http://creativecommons.org/licenses/by/4.0/), which permits unrestricted reuse of the work in any medium, provided the original work is properly cited. [DOI: 10.1149/2.0052001JSS]

(cc) BY
\end{abstract}

Manuscript submitted May 24, 2019; revised manuscript received July 7, 2019. Published September 12, 2019. This paper is part of the JSS Focus Issue on Recent Advances in Wide Bandgap III-Nitride Devices and Solid State Lighting: A Tribute to Isamu Akasaki.

The environmental and economic benefits of phosphor-converted white light emitting diodes (pc-WLEDs) have been increasingly appreciated in recent years. An important challenge in this field pertains to developing phosphors emitting in the red wavelength region, under excitation in either the near-UV range $(380-410 \mathrm{~nm})$ or the blue range $(450-480 \mathrm{~nm})$. Amongst the most promising red phosphors, particularly important are those based on intraconfigurational $4 \mathrm{f}-4 \mathrm{f}$ transitions of $\mathrm{Eu}^{3+}$. Great attention has been paid on $\mathrm{Eu}^{3+}$-doped molybdates (e.g., $\mathrm{BaGa}_{2}\left(\mathrm{MoO}_{4}\right)_{4}: \mathrm{Eu}^{3+},{ }^{1}$ and $\left.\mathrm{NaEu}\left(\mathrm{MoO}_{4}\right)_{2}: \mathrm{Eu}^{3+2}\right)$, tungstates (e.g., $\left.(\mathrm{La}, \mathrm{Eu}, \mathrm{Sm})_{2} \mathrm{~W}_{3} \mathrm{O}_{12}{ }^{3}\right)$, borosilicates (e.g., $\quad \mathrm{Eu}_{0.14} \mathrm{Mg}_{0.18} \mathrm{Ca}_{0.07} \mathrm{Ba}_{0.12} \mathrm{~B}_{0.17} \mathrm{Si}_{0.32} \mathrm{O}_{\delta}{ }^{4}$ ), titanates (e.g., $\left.(\mathrm{K}, \mathrm{Li}, \mathrm{Na})_{\mathrm{x}}(\mathrm{Y}, \mathrm{Gd}, \mathrm{La}, \mathrm{Eu})_{\mathrm{y}} \mathrm{Ti}_{\mathrm{z}} \mathrm{O}_{\delta}{ }^{5}\right)$, and vanadates (e.g., $\mathrm{BiSr}_{2} \mathrm{~V}_{3} \mathrm{O}_{11}: \mathrm{Eu}^{3+}, \quad \mathrm{Ca}_{2} \mathrm{NaMg}_{2} \mathrm{~V}_{3} \mathrm{O}_{12}: \mathrm{Eu}^{3+}$, and $\left.\mathrm{Ca}_{3} \mathrm{Sr}_{3}\left(\mathrm{VO}_{4}\right)_{4}\right){ }^{6-12}$ Other reports on red emission in $\mathrm{K}_{2} \mathrm{SiF}_{6}: \mathrm{Mn}^{4+}{ }^{13}$ (Ca,Ba)ZnOS: $\mathrm{Mn}^{2+},{ }^{14,15} \mathrm{CaAlSiN}_{3}: \mathrm{Eu}^{2+},{ }^{16}$ and $\mathrm{Sr}\left[\mathrm{LiAl}_{3} \mathrm{~N}_{4}\right]: \mathrm{Eu}^{2+},{ }^{17}$ are other noticeable contributions in the field.

Of specific concern for this work is the red-emitting vanadate phosphor $\mathrm{Ca}_{9} \mathrm{Eu}\left(\mathrm{VO}_{4}\right)_{7}$, which is built up of a whitlockite-type crystal structure of $\mathrm{VO}_{4}$ tetrahedra with the $\mathrm{Ca} / \mathrm{Eu}$ atoms occupying the space between the tetrahedral groups, and with a random distribution of $\mathrm{Eu}^{3+}$ ions on four individual Ca crystallographic sites. ${ }^{18-21}$ The PL excitation spectrum of $\mathrm{Ca}_{9} \mathrm{Eu}\left(\mathrm{VO}_{4}\right)_{7}$ exhibits a strong absorption band between 250 and $310 \mathrm{~nm}$ in the UV region, attributable to charge transfer of $\mathrm{V}-\mathrm{O}$ type inside $\mathrm{VO}_{4}^{3-}$ groups, and some sharp lines between 350 and $500 \mathrm{~nm}$ due to various intra-configurational $4 \mathrm{f}-4 \mathrm{f}$ transitions of $\mathrm{Eu}^{3+} .{ }^{18}$ Under near UV excitation, higher lying $4 \mathrm{f}^{6}$ levels transfer energy to the ${ }^{5} \mathrm{D}_{0}$ level by nonradiative processes, leading to intense red emission at $614 \mathrm{~nm}$ due to the forced electric dipole allowed ${ }^{5} \mathrm{D}_{0} \rightarrow{ }^{7} \mathrm{~F}_{2}$ transitions of the $\mathrm{Eu}^{3+}$ ions. ${ }^{22}$ The red emission has been shown to exhibit a relatively high thermal stability with respect to other inorganic phosphors. At T $=420 \mathrm{~K}$, approximately $20-25 \%$ of the luminescence intensity as measured at room temperature is lost, for excitation in the

\footnotetext{
${ }^{\text {a}}$ Present address: Institute of Applied Physics, TU Bergakademie Freiberg, 09599 Freiberg, Germany.

bPresent address: Helmholtz-Zentrum Dresden-Rossendorf, Helmholtz Institute Freiberg for Resource Technology, 09599 Freiberg, Germany.

${ }^{c}$ Present address: Advanced Technology Institute, Department of Electrical and Electronic Engineering, University of Surrey, Guildford GU2 7XH, United Kingdom.

${ }^{\text {zE} E-m a i l: ~ m a t h s . k a r l s s o n @ c h a l m e r s . s e ~}$
}

UV to blue range, with no shift in the emission wavelengths, ${ }^{18,22,23}$ suggesting it would be suitable for application in pc-WLEDs. However, the performance of $\mathrm{Ca}_{9} \mathrm{Eu}\left(\mathrm{VO}_{4}\right)_{7}$ phosphor integrated on a LED base has not yet been evaluated, and thus key technological aspects, such as the luminous efficacy of optical radiation (LER) and color/intensity stability under typical pc-WLED operating conditions remain unclear. For this reason, here we investigate the PL properties, such as the excitation and emission spectra and thermal stability, of $\mathrm{Ca}_{9} \mathrm{Eu}\left(\mathrm{VO}_{4}\right)_{7}$ phosphor under excitation in the near-UV range, as well as we evaluate the performance of a pc-LED prototype comprising a near-UV LED and $\mathrm{Ca}_{9} \mathrm{Eu}\left(\mathrm{VO}_{4}\right)_{7}$ phosphor.

\section{Experimental}

Materials synthesis.-The sample, $\mathrm{Ca}_{9} \mathrm{Eu}\left(\mathrm{VO}_{4}\right)_{7}$, was prepared by a conventional solid state synthesis route by mixing stoichiometric amounts of the starting reactants $\mathrm{CaCO}_{3}, \mathrm{Eu}_{2} \mathrm{O}_{3}$, and $\mathrm{V}_{2} \mathrm{O}_{5}$. The raw materials were pelletized under a load of 10 tons and underwent three thermal treatments in air at $350^{\circ} \mathrm{C}(5$ hours $), 700^{\circ} \mathrm{C}$ (5 hours) and $1000^{\circ} \mathrm{C}$ for 10 hours, with intermediate grindings. The as-sintered sample was pulverized and used as is for further studies.

Powder X-ray diffraction.-Powder X-ray diffraction (PXRD) measurements were performed on an X'TRA powder diffractometer with a Cu-anode X-ray source $(\lambda=1.5406 \AA)$, operating in the Bragg-Brentano geometry. The PXRD pattern was collected in the $20-70^{\circ} 2 \theta$-range at a scan speed of $0.03 \%$ s.

Photoluminescence spectroscopy.-The PL excitation and emission spectra were measured at room temperature using a Fluorolog 3 spectrofluorometer from Horiba-Jobin-Yvon, equipped with a Xe lamp, a double excitation monochromator, a single emission monochromator (model HR320) and a photomultiplier tube (PMT) in photon counting mode for the detection of the emitted signal. Diffuse reflectance spectra were measured with the use of a halogen lamp.

Variable temperature emission intensity measurements were performed over the temperature range $\mathrm{T}=300-800 \mathrm{~K}$, using a Linkam THMS 600 heating stage, with the sample prepared as a discshaped pellet of $5 \mathrm{~mm}$ in diameter by uniaxial pressing of $60 \mathrm{mg}$ $\mathrm{Ca}_{9} \mathrm{Eu}\left(\mathrm{VO}_{4}\right)_{7}$ phosphor. The excitation was obtained using a $454 \mathrm{~nm}$ 
DeltaDiode DD-450L laser connected to a DD-C1 picosecond diode controller from Horiba Scientific. Emission spectra were recorded on an Ocean Optics USB2000+ UV-Vis spectrometer.

Phosphor-converted red LED prototypes.-Red-emitting pc-LED prototypes were developed by integrating $\mathrm{Ca}_{9} \mathrm{Eu}\left(\mathrm{VO}_{4}\right)_{7}$ phosphor powder on near-UV LED chips as purchased from Semileds Corporation. The LED chip dimensions were $400 \times 400 \mu \mathrm{m}^{2}$ and featured a $115 \mu \mathrm{m}$ bond pad on the surface and an Au-plated back side. The active region consisted of InGaN epi-layers with an emission maximum at $396 \mathrm{~nm}$. The LEDs were capable of delivering $20 \mathrm{~mA}$ at $3.8 \mathrm{~V}$ forward voltage with a junction temperature of $125^{\circ} \mathrm{C}$. Au-plated Schott 8 pin $\mathrm{TO}_{5}$ headers were used as LED holders. Mounting was done using In-204 soldering paste from Indium Corporation and heating the headers on a hot plate to $200^{\circ} \mathrm{C}$ before mechanical transfer of the LED chip to the header. Another heating to $200^{\circ} \mathrm{C}$ was performed with the LED chip mounted. Contacts to two of the pins were made from the LED top bond pad as well as the back side of the Au-plated chip using a K\&S 4123 wedge bonder and $17 \mu \mathrm{m}$ Au-wire.

The $\mathrm{Ca}_{9} \mathrm{Eu}\left(\mathrm{VO}_{4}\right)_{7}$ phosphor was dispersed in Elastosil RT 601 silicone gel procured from Wacker Chemicals. Elastosil RT 601A and 601B components were mixed in a 10:1 ratio. After component mixing, $75 \mu l$ of the gel was mixed with different ratios of phosphor powder. A series of five samples with a phosphor concentration of $133,270,400,530$, and $670 \mathrm{~g} / 1$ silicone gel was prepared. These gels were then mechanically transferred to the headers to coat the LED and left to solidify overnight. A reference LED, of $75 \mu \mathrm{l}$ pure silicone gel (without phosphor), was prepared in order to measure the absorption of the silicone gel alone. For the reproducibility of results, all the $75 \mu \mathrm{l}$ of gel + phosphor was applied to the LEDs. The 8-pin headers with the coated LEDs were mounted in an Optronic Laboratories OL 770 Multichannel spectroradiometer integrating sphere for the optical measurements. Current was supplied using a Yokogawa 7651 Programmable DC source and simultaneous voltage was measured using a Keithley 2400 SourceMeter (to monitor the maximum allowed voltage of the LEDs).

\section{Results and Discussion}

Powder X-ray diffraction.-Fig. 1a shows the room temperature PXRD pattern of $\mathrm{Ca}_{9} \mathrm{Eu}\left(\mathrm{VO}_{4}\right)_{7}$ phosphor sample along with Rietveld refinement of the PXRD pattern. The PXRD pattern shows that the sample is single-phase with no detectable amounts of impurities, having a chi-square value of 2.52 . In agreement with previous studies of $\mathrm{Ca}_{9} \mathrm{Eu}\left(\mathrm{VO}_{4}\right)_{7}$, the PXRD pattern can be indexed to a whitlockite-type structure (space group $R 3 c$ ) with a hexagonal unit cell built up of $\mathrm{VO}_{4}$ tetrahedra with the $\mathrm{Ca} / \mathrm{Eu}$ ions occupying the space between the $\mathrm{VO}_{4}$ tetrahedra, and with the $\mathrm{Eu}^{3+}$ ions randomly distributed on four individual Ca crystallographic sites (Fig. 1b). The unit cell parameters are $a=b=10.8663 \AA$, and $c=38.0863 \AA$, and the unit cell volume is $V=3894.62 \AA^{3}$. These values are in agreement with earlier crystallographic studies of $\mathrm{Ca}_{9} \mathrm{Eu}\left(\mathrm{VO}_{4}\right)_{7} \cdot{ }^{13,18}$

Photoluminescence spectroscopy.-Fig. 2a shows the PL emission and excitation spectra for $\mathrm{Ca}_{9} \mathrm{Eu}\left(\mathrm{VO}_{4}\right)_{7}$, as measured at $\mathrm{T}=$ $293 \mathrm{~K}$. The excitation spectrum (in black color), as measured upon a fixed emission wavelength of $613 \mathrm{~nm}$, is characterized by a broad band that extends from the lower limit of the measured spectrum $(275 \mathrm{~nm})$ up to about $350 \mathrm{~nm}$, which is assigned as ${ }^{1} \mathrm{~A}_{1} \rightarrow{ }^{1} \mathrm{~T}_{2}$ and ${ }^{1} \mathrm{~A}_{1} \rightarrow{ }^{1} \mathrm{~T}_{1}$ charge transfer transitions inside $\mathrm{VO}_{4}^{3-}$ groups. Additionally, the spectrum contains sharper peaks at approximately $380 \mathrm{~nm}\left({ }^{7} \mathrm{~F}_{0} \rightarrow{ }^{5} \mathrm{~L}_{7}\right)$, $395 \mathrm{~nm}\left({ }^{7} \mathrm{~F}_{0} \rightarrow{ }^{5} \mathrm{~L}_{6}\right), 414 \mathrm{~nm}\left({ }^{7} \mathrm{~F}_{0} \rightarrow{ }^{5} \mathrm{D}_{3}\right)$, and $464 \mathrm{~nm}\left({ }^{7} \mathrm{~F}_{0} \rightarrow{ }^{5} \mathrm{D}_{2}\right)$, respectively. ${ }^{23}$ The excitation spectrum is in good agreement with the diffuse reflectance spectrum, as reported in Fig. 2b. The intense transitions at 395 and $464 \mathrm{~nm}$, respectively, are important for application of $\mathrm{Ca}_{9} \mathrm{Eu}\left(\mathrm{VO}_{4}\right)_{7}$ as a color converter in LEDs as they overlap with the emission from near-UV and blue LEDs, respectively.

The PL emission spectrum (in red color in Fig. 2a) was measured for excitation at $395 \mathrm{~nm}$ in order to mimic the experimental conditions for the pc-LED prototype based on a near-UV LED and
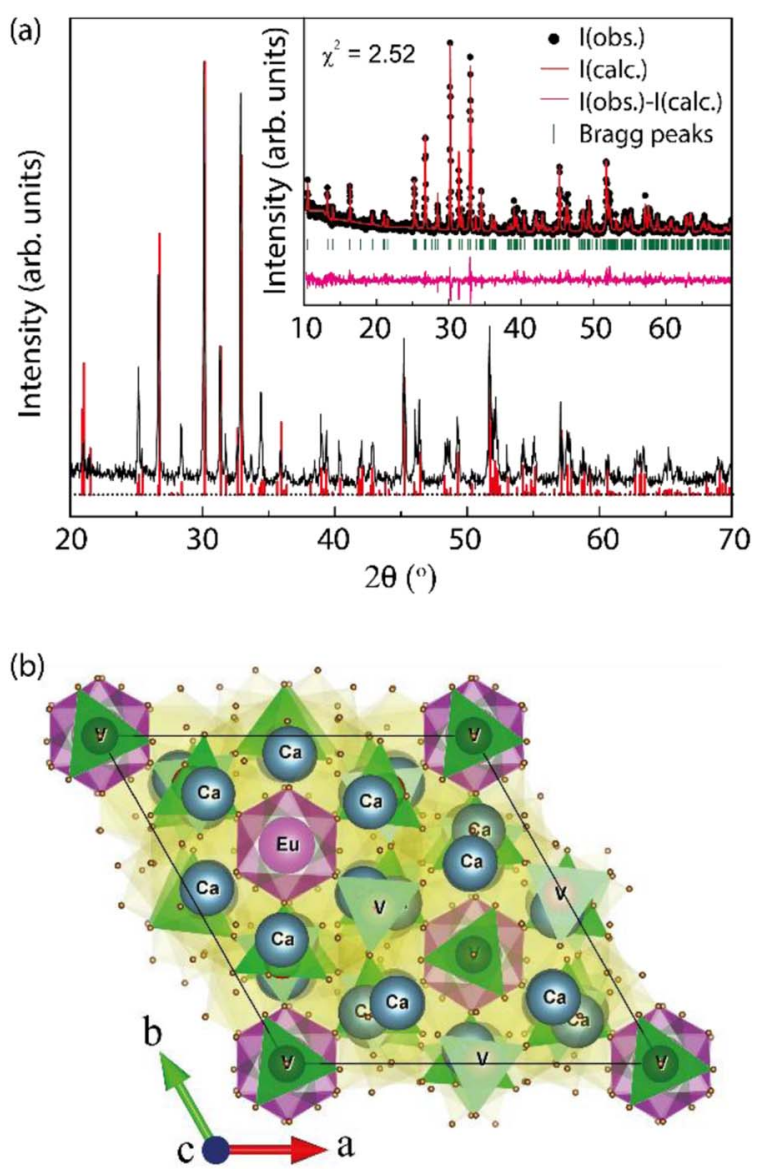

Figure 1. (a) PXRD pattern of $\mathrm{Ca} 9 \mathrm{Eu}\left(\mathrm{VO}_{4}\right)_{7}$. The black curve shows the experimental data and the red curve calculated data for the whitlockite-type crystal structure. The inset shows the difference between the observed and calculated intensity from crystal structure refinement using the Rietveld method. (b) Schematic diagram of the whitlockite-type crystal structure of $\mathrm{Ca}{ }_{9} \mathrm{Eu}\left(\mathrm{VO}_{4}\right)_{7}$, with atomic labels.

$\mathrm{Ca}_{9} \mathrm{Eu}\left(\mathrm{VO}_{4}\right)_{7}$ phosphor, as described below. The spectrum contains two particularly strong emission lines, at $613 \mathrm{~nm}\left({ }^{5} \mathrm{D}_{0} \rightarrow{ }^{7} \mathrm{~F}_{2}\right)$ and $700 \mathrm{~nm}\left({ }^{5} \mathrm{D}_{0} \rightarrow{ }^{7} \mathrm{~F}_{4}\right)$, respectively, in agreement with the literature. ${ }^{23}$

Fig. 2c shows the PL emission spectra $(550-750 \mathrm{~nm})$, as a function of temperature from room temperature up to $\mathrm{T}=793 \mathrm{~K}$, for excitation at $454 \mathrm{~nm}$. The intensity of the emitted light decreases systematically with increasing temperature. Nevertheless, virtually no shift in wavelength of the emission bands is observed, the latter being an important characteristic for technological applications. The PL emission spectra also showed some background in the 550-575 $\mathrm{nm}$ region, which is not observed for excitation at $395 \mathrm{~nm}$, cf. Fig. 2a. The origin of this emission is unclear but may be related to the sensitization of $\mathrm{Eu}^{3+}$ emission under $454 \mathrm{~nm}$ excitation as this wavelength region also corresponds to the emission from the lowest ${ }^{3} \mathrm{~T}_{2} \rightarrow{ }^{1} \mathrm{~A}_{1}$ and ${ }^{3} \mathrm{~T}_{1} \rightarrow{ }^{1} \mathrm{~A}_{1}$ transitions of $\mathrm{VO}_{4}{ }^{3-}$ at around 462 and $468 \mathrm{~nm}$ with a total separation of $278 \mathrm{~cm}^{-1}$. 23

Fig. 2d shows the temperature dependence of the emission intensity, as integrated over the wavelength region $605-625 \mathrm{~nm}$, i.e. over the predominant emission line $\left({ }^{5} \mathrm{D}_{0} \rightarrow{ }^{7} \mathrm{~F}_{2}\right.$ band) and normalized to the integrated intensity at the lowest temperature measured $(\mathrm{T}=293 \mathrm{~K})$. The integrated emission intensity decreases quite strongly with increasing temperature from $\mathrm{T}=293 \mathrm{~K}$ to $\mathrm{T}=800 \mathrm{~K}$. At $\mathrm{T}=423 \mathrm{~K}$, the integrated emission intensity maintains about $65 \%$ of that measured at room temperature, which is similar to the previous report by Liu et al. ${ }^{18}$ (cf. $78 \%$ of the room-temperature intensity retained at $\mathrm{T}=$ $423 \mathrm{~K}$, under excitation at $465 \mathrm{~nm}$ ). The thermal quenching temperature, which is defined here as the temperature at which the PL intensity has dropped to $50 \%$ of the low-temperature value, is $\mathrm{T}_{50 \%} \approx 470 \mathrm{~K}$. 

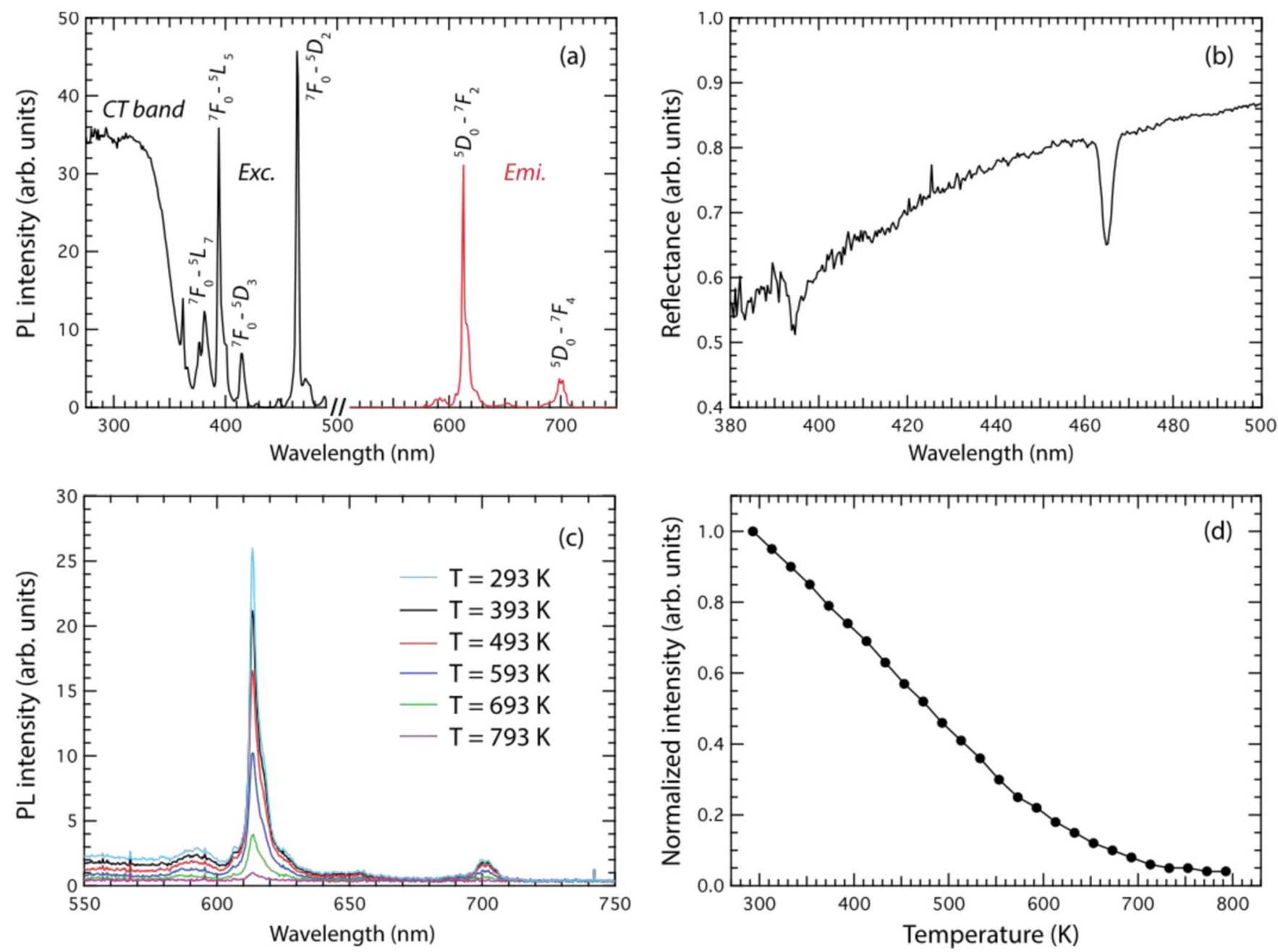

Figure 2. (a) PL spectra of $\mathrm{Ca} 9 \mathrm{Eu}\left(\mathrm{VO}_{4}\right)_{7}$ phosphor. The excitation (Exc.) spectrum was measured upon a fixed emission wavelength of $613 \mathrm{~nm}$, and the emission (Emi.) spectrum was measured upon excitation at $395 \mathrm{~nm}$. (b) Diffuse reflectance spectrum of $\mathrm{Ca}_{9} \mathrm{Eu}\left(\mathrm{VO}_{4}\right)_{7}$ phosphor between 380 and $500 \mathrm{~nm}$. (c) PL emission spectra of $\mathrm{Ca}_{9} \mathrm{Eu}\left(\mathrm{VO}_{4}\right)_{7}$ phosphor, as a function of temperature, for excitation at $454 \mathrm{~nm}$. (d) Temperature dependence of the normalized emission intensity for $\mathrm{Ca} 9 \mathrm{Eu}\left(\mathrm{VO}_{4}\right)_{7}$ phosphor under excitation at $454 \mathrm{~nm}$.

Table I. Upper panel: compilation of measured emission peak intensities for an uncoated near-UV (395 nm) LED(column 2), and for the near-UV LED coated with pure silicone gel (column 3$)$. Column 4 shows the peak $(395 \mathrm{~nm})$ emission intensity loss due to the silicone coating. Lower panel: Total intensity of the bare near-UV LED (column 2) and of the red-LED prototypes after phosphor+silicone coating (column 3), total emission intensity loss upon comparison of intensities in column 2 and 3 (column 4); and external quantum efficiency (EQE) for the phosphor-coated red-LED prototypes (column 5). The total emission intensities were measured using an integrating sphere.

\begin{tabular}{|c|c|c|c|c|}
\hline Current (mA) & Intensity near-UV LED (a.u.) & \multicolumn{2}{|c|}{ Intensity silicone-gel-coated near-UV LED (a.u.) } & Emission loss due to silicone coating (\%) \\
\hline 1 & $4.92 \times 10^{-6}$ & $3.15 \times 10^{-6}$ & & 36 \\
\hline 2 & $2.09 \times 10^{-5}$ & $1.47 \times 10^{-5}$ & & 30 \\
\hline 3 & $4.33 \times 10^{-5}$ & $3.13 \times 10^{-5}$ & & 28 \\
\hline 5 & $9.79 \times 10^{-5}$ & $7.22 \times 10^{-5}$ & & 26 \\
\hline $\begin{array}{l}\text { Phosphor } \\
\text { concen. (g/l) }\end{array}$ & $\begin{array}{l}\text { Intensity } \\
\text { near-UV LED (a.u.) }\end{array}$ & $\begin{array}{l}\text { Intensity red-LED } \\
\text { prototype (a.u.) }\end{array}$ & $\begin{array}{l}\text { Emission intensity } \\
\text { loss }(\%)\end{array}$ & $\mathrm{EQE}(\%)$ \\
\hline 133 & $8.95 \times 10^{-5}$ & $1.97 \times 10^{-5}$ & 78 & 7.33 \\
\hline 270 & $6.39 \times 10^{-5}$ & $3.62 \times 10^{-6}$ & 94 & 8.13 \\
\hline 400 & $8.80 \times 10^{-5}$ & $1.43 \times 10^{-6}$ & 98 & 6.53 \\
\hline 530 & $7.95 \times 10^{-5}$ & $2.65 \times 10^{-7}$ & 97 & 5.63 \\
\hline 670 & $9.13 \times 10^{-5}$ & $2.52 \times 10^{-8}$ & 99.9 & 4.13 \\
\hline
\end{tabular}


(a)

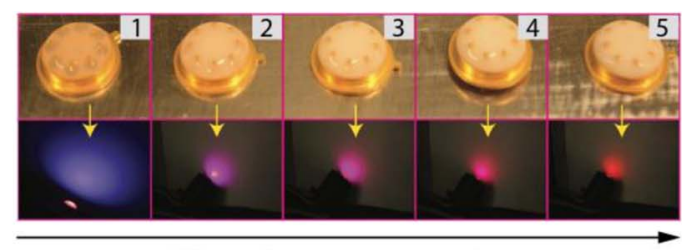

Phosphor concentration
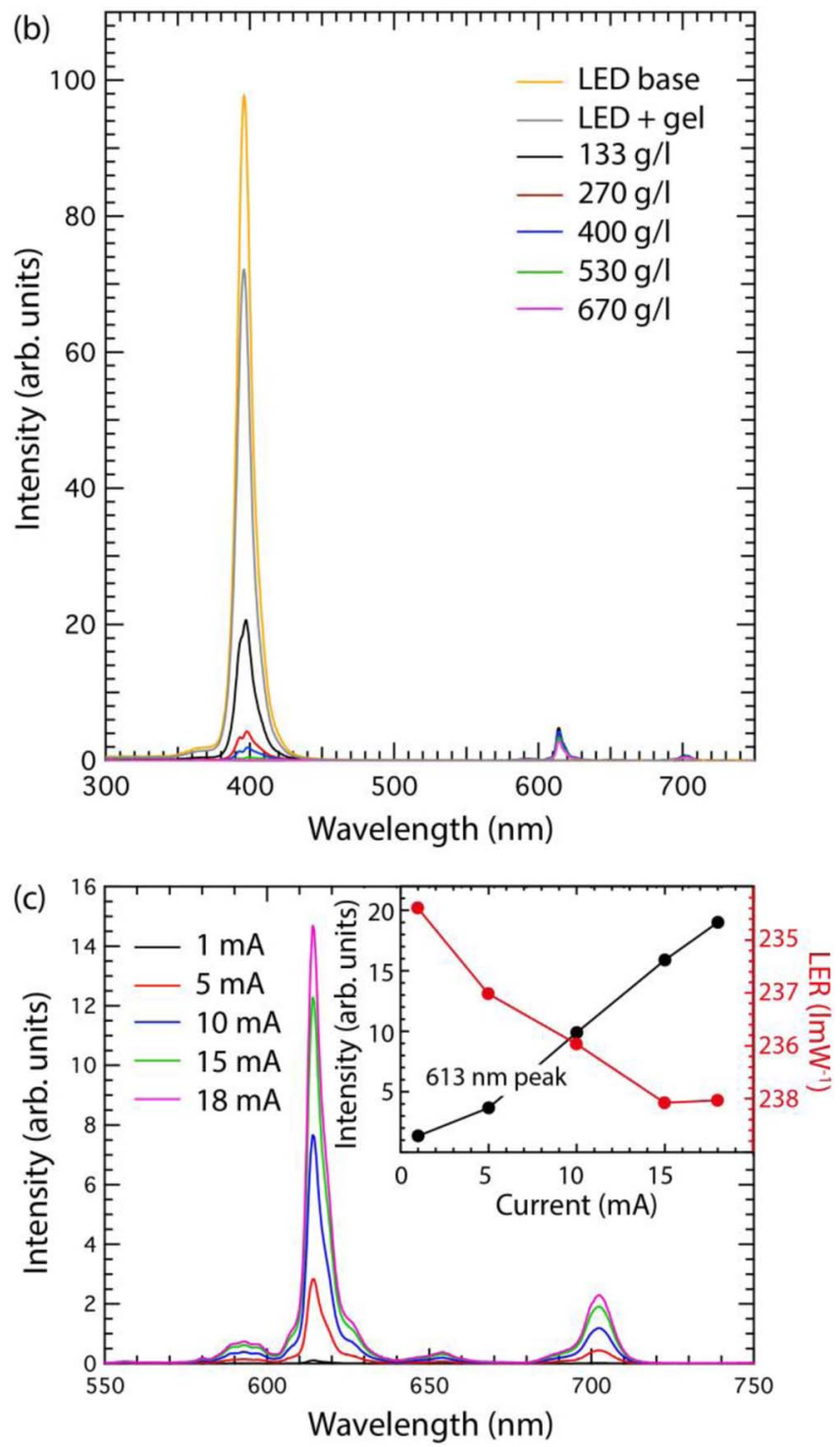

Figure 3. (a) Photographs of the pc-LED prototypes with a phosphor to silicone gel concentration of (1) $133 \mathrm{~g} / \mathrm{l}$, (2) $270 \mathrm{~g} / \mathrm{l}$, (3) $400 \mathrm{~g} / \mathrm{l}$, (4) $530 \mathrm{~g} / \mathrm{l}$, and (5) $670 \mathrm{~g} / \mathrm{l}$, under a current supply of $5 \mathrm{~mA}$. (b) Emission spectra of the pcLED prototype coated with different phosphor to silicone gel concentrations, under operation with a current of $5 \mathrm{~mA}$. (c) Emission spectra of the pc-LED prototype, with a phosphor concentration of $670 \mathrm{~g} / \mathrm{l}$, as a function of applied current. Inset shows a graph of the integrated emission from 600 to $635 \mathrm{~nm}$ as a function of applied current (black), and the LER (red).

Red-LED prototype.-Fig. 3a shows photographs of red LED prototypes coated with the five different phosphor-to-silicone-gel concentrations, under $5 \mathrm{~mA}$ current supply. A trend of a decreasing violet emission $(395 \mathrm{~nm})$ from the LED base and an increasing intensity of the red emission $(613 \mathrm{~nm})$ as a function of increasing phosphor concentration is observed, Fig. 3b. For the phosphor concentration of $270 \mathrm{~g} / \mathrm{l}$, the peak intensities of the 395 and $613 \mathrm{~nm}$ bands are almost the same, whereas for higher phosphor concentrations, the red emission dominates. For the highest phosphor concentration $(670 \mathrm{~g} / \mathrm{l})$, the violet light is completely absorbed by the phosphor and only red-light emission is observed.

Fig. $3 c$ shows the emission spectra over the red wavelength region for the highest phosphor concentration $(670 \mathrm{~g} / \mathrm{l})$ as a function of increasing current of the LED base. The spectra show a general increase in intensity as a function of increasing current supply. The integrated intensity over this spectral range shows a linear response with increasing current (inset).

To further investigate the nature of the emission from the red-LED prototypes, we examined the light output with respect to the individual LEDs used for each prototype. For a power supply of $5 \mathrm{~mA}$, the five LEDs showed slightly different output intensity; see Table I, which also contains the relevant data for the LEDs coated with phosphor. The violet emission $(395 \mathrm{~nm})$ decreases by $78 \%$ for the lowest to $99.9 \%$ for the highest phosphor to silicone gel concentration. While some decrease (about $30 \%$ ) can be attributed to absorption in the pure silicone gel, the observed decrease mainly is a consequence of the low $\mathrm{Eu}^{3+} f-f$ absorption strength. Furthermore, a portion of the $395 \mathrm{~nm}$ photons will be converted to $613 \mathrm{~nm}$ photons, however, we observe that the output intensity at $613 \mathrm{~nm}$ is found to be highest for the prototype with the lowest phosphor concentration and shows a trend of a slightly decreasing intensity for higher concentrations. By assuming that the emission intensity at $613 \mathrm{~nm}$ encompasses all the red emission from the LED prototypes, the external quantum efficiency (EQE) which is proportional to the ratio of the number of emitted photons and the number of absorbed photons, is found to be decreasing from 7.33 to $4.13 \%$ for the LED with the lowest phosphor content to the highest phosphor content, Table I - last column (lower panel). The electrons in the f-orbital of the $\mathrm{Eu}^{3+}$ ion are shielded from their surroundings, and are largely unaffected by the external bonding which manifests spectra with very narrow bands in the excitation and emission spectra. Upon comparison of the EQE between $\mathrm{Eu}^{3+}$ doped samples, and those with $\mathrm{Mn}^{4+}$ and $\mathrm{Eu}^{2+}$ doped samples, ${ }^{13-17}$ one can clearly observe the higher EQE for the later ones. This can be considered as a downside of the $\mathrm{Eu}^{3+}$ excitation as it is very sensitive to the host-dopant mismatch and require materials with wider bandgap for providing energy migration channels for $\mathrm{Eu}^{3+}$ excitation.

The LER or the brightness of the light as emitted by the red-LED prototypes, as perceived by the average human was calculated according to the following relationship:

$$
L E R=6831 \mathrm{~m} / \mathrm{W} \cdot \frac{\int_{\lambda=360 \mathrm{~nm}}^{\lambda=830 \mathrm{~m}} I(\lambda) V(\lambda) d \lambda}{\int_{\lambda=360 \mathrm{~nm}}^{\lambda=830 \mathrm{~mm}} I(\lambda) d \lambda}
$$

where the prefactor $683 \mathrm{~lm} / \mathrm{W}$ is a normalization factor, $\mathrm{V}(\lambda)$ is the eye sensitivity, and $I(\lambda)$ the emission spectrum. ${ }^{24}$ Under an applied current of $1 \mathrm{~mA}$, the prototype with the highest phosphor concentration exhibits a LER of $238 \mathrm{~lm} / \mathrm{W}$, which decreased only very slightly, to $235 \mathrm{~lm} / \mathrm{W}$, when increasing the current to $18 \mathrm{~mA}$ (Fig. 3c, inset), suggesting a high stability of luminescence toward increasing current of the LED base.

The colors of the emitted light from the five LED prototypes were further evaluated using a CIE 1931 color space diagram (Fig. 4). The color evolves from being dominated by the violet emission from the LED base at the lowest phosphor concentration to bright red color for the highest phosphor concentration, i.e. very close to the red edge of the color space diagram. Furthermore, we observe that the emission spectrum is dominated by the strong emission band at $613 \mathrm{~nm}\left({ }^{5} \mathrm{D}_{0} \rightarrow{ }^{7} \mathrm{~F}_{2}\right)$, whereas the other emission band at approximately $700 \mathrm{~nm}\left({ }^{5} \mathrm{D}_{0} \rightarrow{ }^{7} \mathrm{~F}_{4}\right)$ is much weaker, resulting in a high color purity. The high color purity, temperature stability, and LER makes $\mathrm{Ca}_{9} \mathrm{Eu}\left(\mathrm{VO}_{4}\right)_{7}$ a highly promising phosphor for technological applications.

\section{Conclusions}

To conclude, our results establish that the emission spectrum of the red-emitting phosphor $\mathrm{Ca}_{9} \mathrm{Eu}\left(\mathrm{VO}_{4}\right)_{7}$ is dominated by a sharp emission 


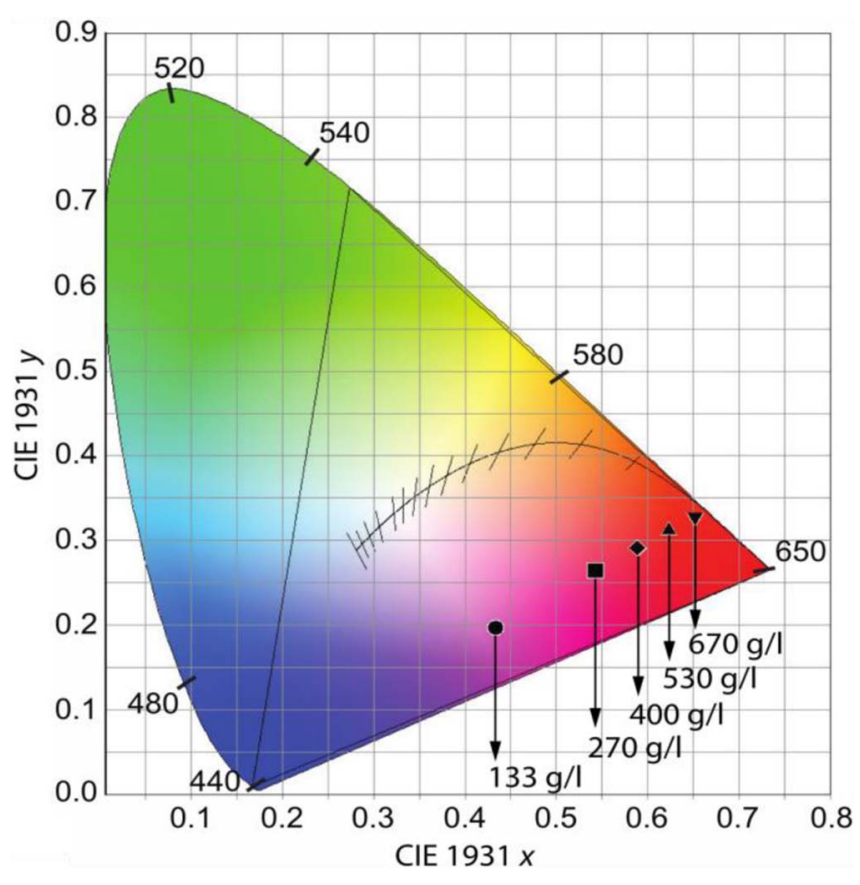

Figure 4. CIE 1931 color coordinate diagram for the five different pc-LED prototypes based on $\mathrm{Ca} 9 \mathrm{Eu}\left(\mathrm{VO}_{4}\right)_{7}$ phosphor and a near-UV LED [CIE 1931, $(x, y)=(0.434,0.197)$ for $133 \mathrm{~g} / \mathrm{l},(0.544,0.264)$ for $270 \mathrm{~g} / \mathrm{l},(0.589,0.291)$ for $400 \mathrm{~g} / \mathrm{l},(0.624,0.312)$ for $530 \mathrm{~g} / \mathrm{l}$, and $(0.652,0.328)$ for $670 \mathrm{~g} / 1]$ under $5 \mathrm{~mA}$ current supply at $\mathrm{T}=300 \mathrm{~K}$.

band at $613 \mathrm{~nm}$ under excitation with near-UV light $(395 \mathrm{~nm})$. The data presented in the work demonstrates that the $\mathrm{Eu}^{3+}$-based phosphor has significant issues with respect to practical implementation. The color of the emitted light is stable upon increasing temperature from $\mathrm{T}=293$ to $\mathrm{T}=793 \mathrm{~K}$, but shows a strong decrease in the emitted intensity. At $\mathrm{T}=420 \mathrm{~K}$, the integrated intensity of the $613 \mathrm{~nm}$ emission band has decreased to about $65 \%$ of that at room temperature, and at $\mathrm{T}=470 \mathrm{~K}$ it has decreased to about $50 \%$. Furthermore, the performance of $\mathrm{Ca}_{9} \mathrm{Eu}\left(\mathrm{VO}_{4}\right)_{7}$ phosphor was evaluated by coating the phosphor on near-UV LED chips with silicone gel as an encapsulating agent. By this relatively simple phosphor capping technique, we obtain red-LEDs featuring a high red color purity and thermal stability.

\section{Acknowledgments}

Financial support from the Swedish Research Council Formas (grant No. 2013-1723), and the European Commission for funding through the Marie Curie Initial Training Network LUMINET (grant No. 316906) is gratefully acknowledged. We also thank Erica Viviani (University of Verona) for expert technical assistance.

\section{ORCID}

Suchinder K. Sharma (D https://orcid.org/0000-0002-8351-4597 Maths Karlsson (D) https://orcid.org/0000-0002-2914-6332

\section{References}

1. C. F. Guo, H.-K. Yang, Z. L. Li, L. Fu, B.-C. Choi, and J.-H. Jeong, J. Am. Ceram. Soc., 92, 1713 (2009).

2. Z. L. Wang, H. B. Liang, J. Wang, M. L. Gong, and Q. Su, Appl. Phys. Lett., 89, 0719211-1-3 (2006).

3. S. Okamoto and H. Yamamoto, Electrochem. Solid-State Lett., 10, J139 (2007).

4. K.-S. Sohn, J. M. Lee, and N. Shin, Adv. Mater., 15, 2081 (2003).

5. K.-S. Sohn, D. H. Park, S. H. Cho, J. S. Kwak, and N. Shin, Chem. Mater, 18, 1768 (2006).

6. R. Jagannathan, J. Lumin., 68, 211 (1996)

7. J. H. Kang, W. B. Im, D. C. Lee, J. Y. Kim, D. Y. Jeon, Y. C. Kang, and K. Y. Jung, Solid State Commun. 133, 651 (2005).

8. A. Setlur, H. A. Comanzo, A. M. Srivastava, and W. W. Beers, J. Electrochem. Soc., 152, H205 (2005).

9. B. Yan and X. Q. Su, Opt. Mater., 29, 547 (2007).

10. G. Gundiah, Y. Shimomura, N. Kijima, and A. K. Cheetham, Chem. Phys. Lett., 455, 279 (2008).

11. T. Nakajima, M. Isobe, T. Tsuchiya, Y. Ueda, and T. Kumagi, J. Lumin., 129, 1598 (2009).

12. S. Choi, Y. M. Moon, K. Kim, H. K. Jung, and S. Nahm, J. Lumin., 129, 988 (2009).

13. H. F. Sijbom, R. Verstraete, J. J. Joos, D. Poelman, and P. F. Smet, Opt. Mater. Express, 7, 3332 (2017).

14. J. J. Joos, K. Lajaeghere, K. Korthout, A. Feng, D. Poelman, and P. F. Smet, Phys. Chem. Chem. Phys., 19, 9075 (2017).

15. C. J. Duan, A. C. A. Delsing, and H. T. Hintzen, Chem. Mater, 21, 1010 (2009).

16. K. Uheda, N. Hirosaki, Y. Yamamoto, A. Naito, T. Nakajima, and H. Yamamoto, Electrochem. Solid-State Lett., 9, H22 (2006).

17. P. Pust, V. Weiler, C. Hecht, A. Tücks, A. S. Wochnik, A.-K. Hen $\beta$, D. Wiechert, C. Scheu, P. J. Schmidt, and W. Schnick, Nat. Mater, 13, 891 (2014).

18. L. Liu, R.-J. Xie, N. Hirosaki, Y. Li, T. Takeda, C.-N. Zhang, J. Li, and X. Sun, J. Am. Ceram. Soc., 93, 4081 (2010).

19. A. A. Belik, V. A. Morozov, S. S. Khasanov, and B. I. Lazoryak, Crystallogr. Rep+., 42, 751 (1997).

20. L. X. Huang, N. F. Zhuang, G. Zhang, J. Z. Chen, C. H. Huang, B. Zhao, Y. Wei, X. L. Hu, and M. Wei, Opt. Mater., 31, 372 (2008).

21. X. L. Hu, X. Chen, N. F. Zhuang, R. F. Wang, and J. Z. Chen, J. Cryst. Growth, 310, 5423 (2008)

22. X. Wu, Y. Huang, and H. J. Seo, Ceram. Int., 37, 2323 (2011)

23. X. Mi, K. Du, K. Huang, P. Zhou, D. Geng, Y. Zhang, M. Shang, and J. Lin, Mater. Res. Bull., 60, 72 (2014).

24. R. Mirhosseini, S. F. Martin, S. Chhajed, J. Cho, J. Kyu Kim, and F. D. Schubert E., Opt. Express, 17, 10806 (2009) 